\title{
Accounting Boot Camp For College Juniors
}

Mark Myring, Ball State University

William Wrege, Ball State University

Lucinda Van Alst, Ball State University

\begin{abstract}
We describe a day-long introduction to new accounting majors, which we call a boot camp. Boot camp it is an effort to make juniors more aware of their identity, career purposes and learning resources that are now parts of their world, much of which is not covered explicitly in the accounting curriculum. This paper provides an overview of the activities included in our initial boot camp. In addition, we provide information useful in organizing boot camp type activities at other universities.
\end{abstract}

Keywords: Accounting education, curriculum enhancement, career preparation.

\section{INTRODUCTION}

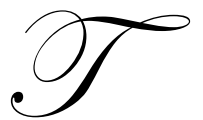

his paper describes a day-long orientation for new accounting majors, which our Department of Accounting calls a boot camp. As the name boot camp suggests from its military roots, it was an effort to offer junior students a brief view of the realities of a professional accounting career, their responsibilities during their last student years and the social networking and other resources that help to build a successful career. Both accounting professors and members of the professional community, most of them our alumni, acted as facilitators for the event. The accounting boot camp was scheduled as a day-long event early in the fall semester. The schedule for the boot camp is included in the Appendix A. The timing of the event was important because we wanted to provide information intended to be helpful in the students' recruiting process, which typically begins in early October.

The purpose of this paper is to share our inaugural event experience, specifically, to provide information about the boot camp's agenda and our students' reactions to it. First, the underlying motivation for the event will be explained and the final program presented. Next, we will provide details about the main program segments, including our efforts to provide networking advice. Finally, based on the initial evaluations made by all of the participants during and after the event, we will offer suggestions for improvements to the program that we are considering for next year.

\section{MOTIVATION FOR THE BOOT CAMP}

At least two years ago some of the accounting faculty members began discussing ways to help new accounting majors realize there increased responsibilities and expectations as they began their professional career preparation. We recognized that some students needed little guidance in establishing workable schedules of coursework, interacting with other students and faculty, and joining our two student organizations, the Accounting Club and Beta Alpha Psi. Those students also interacted well with the many professionals who made presentations at the student organization meetings and, therefore, understood the recruiting process and what was required to be successful. Other students needed more guidance before they can proceed fairly smoothly through the coursework and, eventually, the recruiting process.

Still others seemed reluctant to interact with other students, the faculty or the professionals, which meant they did not always get information that would have assisted them in their academic and professional career preparation. A significant part of the boot camp's motivation was to consistently and clearly provide important information to all new majors, such as academic preparation, successful recruiting experience and related topics. 
Another motive for the boot camp was to provide opportunities for every student to relate with others. The boot camp activities were designed to encourage interactions among the participants. An additional goal was to help the students to identity with the accounting world as professionals as well as with fellow students. The faculty felt that such an identity would foster pride among the group members and within the University. We felt that these were important feelings that would encourage commitment, harder work for a common goal, and ethical behavior.

It was also important to involve our alumni, especially younger alumni who, not long ago, sat in the students' chairs but are now successful, professional business people. We believe their support and the faculty's emphasis that faculty and alumni were there to help them surely encouraged the students. We wanted the students to know that we want them to be successful, and to assure them that they are not alone in their educational quest.

\section{“BOOTING UP” FOR BOOT CAMP}

Our Department of Accounting is fortunate to have two advisory boards. The experienced group of advisors was organized several years ago and, like groups at other universities, is composed of successful professionals, mostly our own alumni. The young alumni group has been in existence for only a little over a year but has embraced its advisory role full-heartedly. The group is composed of recent graduates of our programs, most of them within the last five or fewer years.

When the boot camp idea was first mentioned, the young alum group was very interested in planning the event and participating in its delivery. One of the members volunteered to lead a group in brain-storming ideas for the boot camp. The group's discussion centered on topics identified by the faculty as ones that should be addressed, including academic preparation, professional issues and interviewing for internships and full-time positions. During a later planning session, the group members volunteered to be completely responsible for three segments of the program. Only the academic preparation segment was delivered solely by the faculty.

\section{THE ACCOUNTING CURRICULUM AND THE IMPORTANCE OF YOUR GPA}

During the initial segment of the program, the faculty members discussed the basics of the undergraduate accounting-degree curriculum, including course loads and sequencing. We also discussed how to be successful in accounting courses. We hoped these presentations were primarily a reinforcement of good study and student behavior practices; however, we also assured students that the faculty and advisors were there to help them achieve their goals, and that they should seek out faculty and advisors if they were having curriculum difficulties.

We also discussed the alternative ways to obtain the 150 credit hours needed to sit for the CPA examination. Since the path to accomplishing that is more unstructured than the regular curriculum, students often fail to understand their full range of options. We presented three ways to earn the required 150 credit hours: MS in Accounting, an MBA, and a double major in an undergraduate program. Faculty members discussed the strengths in an educational experience of each route. Students may take comfort knowing they have options, but they were also reminded that they had a responsibility to proactively choose one.

When emphasizing the importance of the GPA, we had a particular advantage with an example we can use at Ball State, viz. in accounting, you can't be a C student, like comedian and alum Dave Letterman (who is a Ball State University alumni) claims, and be prepared well as professional accountants ready to take the CPA exam. The importance of the work requires accounting students to have good basic technical knowledge and skills, and demonstrate that accomplishment via their GPAs. Dave Letterman is charming, witty and very wealthy; but we believe no one ever asked him to prepare his or her tax return following the Internal Revenue Code or financial statements in accordance with generally accepted accounting principles. Doing so takes careful preparation and learning of the standards and techniques used by accountants. The Department was fortunate to have alumni who stood before the students and emphasized the opportunities the students have to study and learn during their course work. 


\section{INVOLVEMENT AND NETWORKING}

The Department's two student organizations, Beta Alpha Phi and Accounting Club, help students to get involved with school activities and learn to demonstrate leadership, as well as team commitment. Participation in those organizations also help students understand career opportunities with a variety of professional organizations from Big Four accounting firms to smaller accounting firms to Governmental units. Many networking and acculturating activities are the focus of these organizations. Accounting Boot Camp gave students the chance to hear faculty and alumni the benefits of being active organizational activities.

Camaraderie with fellow students is invaluable to success in school and leads to later professional networking. Collegial relationships are help students to succeed in their program as well as to develop emotional ties to the university and to the accounting department during these formative years of a college education. We were able to emphasize these relationships to students in Accounting Boot Camp and have these important attributes affirmed by our alumni presenters.

\section{THE IMPORTANCE OF ACCOUNTING INTERNSHIPS}

A segment on accounting internships was presented to make the students aware of the opportunities and benefits of internships and the efforts required to obtain them. The importance of gaining internship experience as part of the education process, as well as how to schedule the internship and still complete the degree in a reasonable amount of time, was discussed. Internships have become a critical step to gaining full-time post graduate employment. More than half of our students who accept employment at international accounting firms have had internship experience. In addition, internships play an important role in the education process, allowing students to apply what they have learned in the classroom to a real world setting. Despite these benefits to students and accounting firms' preference for spring over summer internships, spring internships offer only six credit hours. In our 126 credit hour program, students have to take summer school or course overloads in excess of the normal 15 hours per semester in order to get 126 credit hours in four years. Enrolling in a six hour spring internship puts a student behind by at least nine hours. Being aware of that can help students accommodate that impediment. Both faculty and alumni provided information about internships, the type of work interns can expect to do, the process of obtaining an internship, and how to plan so an internship is possible.

\section{RESUME WRITING AND PERSONAL BEHAVIOR IN THE INTERVIEWING PROCESS}

Early stage accounting students often struggle with interview skills and therefore this section was particularly important. The presenters placed emphasis on preparation for interviews, appropriate dress, and behavior in the interviewing context. Other topics were presented, including an overview of behavioral interviewing methods.

We believe that it was valuable to have this session delivered by young alumni. They have recently completed the recruiting process and by being aware of their firms' recruiting plans and goals they are valuable experts. Certainly, they can bring a reality and enthusiasm to this discussion beyond what faculty can convey. In addition, they interacted with students, which was important networking to both students and firms. The alumni spoke about the importance of preparing for interviews so the interviewers know the students are serious candidates. They discussed softer skills, such as proper dress and manner during an interview. This is often new information for many of our students. They are, in the main, first generation college students in their families. Consequently, discussions about professional-type dress and manner are likely helpful topics to help students' presentation techniques and their confidence levels.

\section{KEYNOTE SPEAKER AND LIGHTER MOMENTS}

Gary Bolinger, CEO of the Indiana CPA society served as the keynote speaker. He discussed the exciting possibilities that are available to young professionals in the field of accounting. 
Two sessions of team building and recreational activities were also included in the boot camp. The purpose of these sessions was to build camaraderie among accounting majors. The faculty thought it was important that our majors felt a connection with the university, department and their classmates. We felt that the team building and recreational activities helped achieve this goal. The boot camp concluded with a raffle for prizes that had been donated by CPA firms.

\section{STUDENTS PERCEPTIONS OF THE BOOT CAMP EXPERIENCE}

Upon the completion of the sessions, boot camp participants were asked to complete a survey focusing on the day's activities. The survey instrument used is included in the Appendix $\mathrm{C}$ of this paper. A total of 36 valid surveys were returned. This represented a $100 \%$ response rate. Of the group that attended tended to be traditional age college students ( $83 \%$ where 22 or younger) and relatively good students (68\% had a GPA of 3.0 or higher).

Participants were asked what factor influenced their choice to become an accounting major. Results of their responses are provided in Table 1. The most common factors that influence the choice of accounting as a major are interest in the field (87.5\% positive responses), the number of job opportunities (71.9\% positive responses) and the level of salaries (59.4\% positive responses). In addition, discussion with family members $(33.4 \%$ positive responses) appear to have impacted the decision to become an accounting major more than discussions with friends (12.5\% positive responses) or discussions with professors (9.4\% positive responses). Finally, $18.8 \%$ reported that the choice of accounting as a major was influenced by research they conducted on their own.

Table 1

Factors Influencing Choice of Accounting as a Major

\begin{tabular}{|l|c|}
\hline \multicolumn{1}{|c|}{ Factor: } & \% Responding Positive \\
\hline Interest in the Field & $87.5 \%$ \\
\hline Number of Job Opportunities & $71.9 \%$ \\
\hline Level of Salaries & $59.4 \%$ \\
\hline Discussions with family members & $33.4 \%$ \\
\hline Research you conducted & $18.8 \%$ \\
\hline Discussions with friends & $12.5 \%$ \\
\hline Discussions with professors & $9.4 \%$ \\
\hline
\end{tabular}

Session participants also provided an evaluation of the quality of the boot camp program and the impact it had on them. Specifically, participants were asked 16 questions that directly evaluated the program. Responses were recorded using a five point scale ( $5=$ strongly agree, $1=$ strongly disagree). The results of this analysis are provided below.

Table 2

Survey of Student Responses

Panel A: Quality of Information Provided

\begin{tabular}{|l|c|c|}
\hline & Mean & S.D. \\
\hline Boot camp increased my understanding of: & & 0.70 \\
\hline What it takes to be a successful accounting major. & 4.56 & 0.77 \\
\hline The accounting curriculum and scheduling. & 4.25 & 0.69 \\
\hline The alternatives to meeting the 150 hour requirement. & 4.63 & 0.85 \\
\hline The importance of accounting internships & 4.53 & 0.86 \\
\hline The process of obtaining an internship & 4.38 & 0.65 \\
\hline The recruitment process & 4.63 & 0.60 \\
\hline Interviewing skills & 4.59 & 0.65 \\
\hline The accounting profession today & 4.41 & 0.77 \\
\hline The importance of obtaining a CPA & 4.34 & 0.80 \\
\hline Different fields of specialization in accounting & 4.41 & \\
\hline
\end{tabular}




\section{Panel B: Other Perceptions}

\begin{tabular}{|c|c|c|}
\hline & Mean & S.D. \\
\hline $\begin{array}{l}\text { After attending boot camp, I feel more confident in my ability to successfully interview } \\
\text { for an accounting position }\end{array}$ & 4.38 & 0.73 \\
\hline Boot camp provided me information that will be helpful in my academic career & 4.34 & 0.69 \\
\hline Boot camp provided me information that will be helpful in my professional career & 4.44 & 0.68 \\
\hline After attending, I feel more confident in my choice of accounting as a major. & 4.66 & 0.74 \\
\hline Boot camp has strengthened the connection I feel with fellow students & 3.78 & 0.94 \\
\hline Boot camp has strengthened the connection I feel with Accounting Department Faculty & 4.22 & 0.69 \\
\hline
\end{tabular}

Results of the survey indicate that participants had a favorable view of the program. As shown in Panel A of Table 2, most agree that boot camp had increased their understanding of what it takes to be a successful accounting major (average response $=4.56$ ). Turning to academic topics, participants tended to believe that boot camp increased their understanding of curricular issues (average response $=4.25$ ) and alternatives to achieve the 150 hour requirement (average response $=4.25$ ). Much of the boot camp session focused on internships and the interview process. Results of the survey suggest that the information provided was helpful to participants. For example, most believed that the information regarding the importance of internships (average response $=4.53$ ) and obtaining internships (average response $=4.38$ ) was relevant. In addition, participants felt that quality information was provided on the topics of recruiting (average response $=4.63$ ) and interviewing skills (average response $=4.59$ ). Finally, the boot camp program provided information regarding the accounting profession today (average response $=4.41$ ), different specializations in accounting (average response $=4.41$ ) and the importance of the CPA (average response $=4.34$ ) that was useful to participants.

Panel B of Table 2 provides additional perceptions participants reported related to the day long boot camp session. Most felt more confident in their choice of accounting as a major (average response $=4.66$ ) and their ability to successfully interview for an accounting position (average response $=4.38$ ). Most agreed that the boot camp activities would be helpful in their academic (average response $=4.34$ ) and college career (average response $=$ 4.44). Finally, most students agreed that boot camp strengthened the connection they feel with the accounting students (average response $=3.78$ ) and the faculty (average response $=4.22$ ). In sum, it appears that the boot camp was well received by the student participants.

\section{CONCLUSIONS AND RECOMMENDATIONS}

Many career paths lie before students with accounting majors. The boot camp introduced the major ones to create awareness and excitement at the possibilities. A panel of successful alumni presented these descriptions and served as models for future possibilities. We believe that the alumni created a special connection between the role of students and the role of successful professionals. After all, the alumni sat in the same chairs as the students a mere few years ago. Indeed, the students who attended the boot camp observed days later (in a classroom exercise to elicit comments) that the diverse set of alumni accountants at the boot camp made a valuable representation of accounting career paths. Those students also commented that information about the 150 credit hour requirement to sit for the CPA examination, importance of internships, accounting curriculum information, importance of networking, and the recent graduates sharing of experiences were strengths of the boot camp experience.

Those students also had recommendations for helpful activities. Those included an opportunity for practice interviews, more one-to-one interaction with alumni representatives, more networking recreational events, and more diverse (as in population groups) representation among the visiting young professionals. The faculty is already considering a 3-hour morning session covering some of the same academic and profession topics, but with the luncheon followed by various interactive workshops the students will register for in advance. The workshops might cover, for example, mock interviews, resume writing, developing presentation skills, etc.

Boot camp for accounting majors can be an informative and fun event. Students receive information about the major and profession. They learn about skills necessary to be successful. They receive a vision of the ultimate outcome of their career choice. We feel that it will become an integral part of our students' education. 
Appendix A: Accounting Boot Camp Agenda

1. Welcome and Introductions

2. Academic Preparation and Opportunities

3. Ice-breaker and/or recreation Activity

4. Internships/Professional Issues-Practitioners and Faculty

i. Internships, Professionalism, and Organizations

1. Internships

a. Extended Job Interview

2. Professionalism

a. Dress

b. Etiquette

c. Relationships

d. Business Knowledge/ Current Events

3. Organizations

Professionalism Certificate/ Credentials

a. Accounting Club/Professional Fraternities

b. AICPA and INCPAS

5. Lunch-The Retreat-Keynote Speaker, Gary Bolinger, CEO, INCPAS

6. Interview/resumes-Practitioners

7. Recreation Activity - team building exercise

8. Panel Session-Practitioners

9. Surveys and prize drawings

Appendix B: Sample PowerPoint Slides

Slide \#1

\section{Stay Informed}

- Read the catalog so you will know your major's requirements

- Ask your advisor(s) if you have questions

- Read the class schedule booklets

- Be attentive to e-mails \& other communications sent to you from your 
Slide \#2

\section{You are \#1}

- Your faculty are here to facilitate your acquisition of the knowledge and skills you'll need to be successful in the accounting profession and to guide you in that process

- However, you are the \#1 person

Slide \#3

\section{Study Hard}

- GPA does matter, unless you are David Letterman

- Your GPA reflects the reservoir of knowledge and skills that you've developed during your education

- Your GPA reflects your ability to learn new

Appendix C: Accounting Boot Camp Survey

Background Information

1. Class rank

__ Junior

_ Senior

__ Graduate

2. Sex

___ Female 
3. Age

$18-20$

- $21-22$

23-30

31-40

_ Over 40

4. Overall GPA

3.50-4.00

3.00-3.49

2.50-2.99

2.00-2.49

Below 2.00

5. Which of the following is your major (if double major, select all that apply)?

Accounting

Finance

Other business major (marketing, management, etc)

__ Non-business major

6. Which factors influenced your selection of accounting as a major (select all that apply)

Interest in the field

_ Number job opportunities

_ Level of salaries

Discussions with family members

_ Discussions with friend

_ Discussions with professor

__ Research you conducted on the field

Others (please list)

7. Do any members of your immediate family hold a bachelor's degree?

Yes

- No

8. Do any members of your immediate family have bachelor's degree in a business field?

No

9. Are any members of your immediate family accountants?

Y Yes

_ No

The following questions relate to your experiences at Accounting Boot Camp.

1. The information provided in Accounting Boot Camp increased my understanding of the courses in the accounting curriculum and scheduling courses so that I may finish my Bachelor's degree with an accounting major in a timely way.

__ Strongly agree

Mildly agree

Neutral

Mildly disagree

_ 
2. After attending Accounting Boot Camp, I better understand the alternatives for achieving the 150 credit hour requirement necessary to take the CPA exam.

Strongly agree

Mildly agree

_ Neutral

_ Mildly disagree

_

3. The Accounting Boot Camp program increased my understanding of what it takes to be successful as an Accounting Major. Strongly agree

__ Mildly agree

__ Neutral

Mildly disagree

__ Strongly disagree

4. My understanding of the recruitment process has been improved as a result of Accounting Boot Camp.

Strongly agree
Mildly agree
_ Neutral
Mildly disagree
Strongly disagree

5. Accounting Boot Camp has provided me information that will improve my interviewing skills.

__ Strongly agree

Mildly agree

_ Neutral

__ Mildly disagree

__ Strongly disagree

6. After attending Accounting Boot Camp, I feel more confident in my ability to successfully interview for accounting position.

Strongly agree
Mildly agree
Neutral
_ Mildly disagree
Strongly disagree

7. The Accounting Boot Camp program increased my understanding the accounting profession today.

__ Strongly agree

___ Mildly agree

_ Neutral

_- Mildly disagree

__ Strongly disagree

8. After attending Accounting Boot Camp, I better understand the importance of obtaining CPA certification.

$\begin{array}{ll} & \text { Strongly agree } \\ \text { Mildly agree } \\ \text { Neutral } \\ \text { Mildly disagree } \\ \text { Strongly disagree }\end{array}$

9. After attending Accounting Boot Camp I now have a better understanding of the importance of obtaining an accounting internship.

Strongly agree

___ Mildly agree

__ Neutral

Mildly disagree

___ Strongly disagree 
10. The Accounting Boot Camp has enhanced my understanding of the process of obtaining an internship.

Strongly agree

Mildly agree

_ Neutral

- Mildly disagree

_

11. I have a better understanding of the different fields of specialization within the accounting profession. Strongly agree

Mildly agree

__ Neutral

- Mildly disagree

__ Strongly disagree

12. I feel that the Accounting Boot Camp provided information that will be helpful in my academic career.

_ Strongly agree

__ Mildly agree

__ Neutral

Mildly disagree

_

13. Accounting Boot Camp has strengthened the connection I feel with fellow students.

___ Strongly agree

Mildly agree

_ Neutral

__ Mildly disagree

__ Strongly disagree

14. Accounting Boot Camp has strengthened the connection I feel with the Accounting Department faculty.

$\begin{array}{ll}\text { __ Strongly agree } & \text { Mildly agree } \\ \text { Neutral } & \text { Mildly disagree } \\ \text { _ } & \text { Strongly disagree }\end{array}$

15. I feel that the Accounting Boot Camp provided information that will be helpful in my professional career.

Strongly agree
Mildly agree
_ Neutral
_ Mildly disagree
Strongly disagree

16. After attending, I am more confident in my choice of accounting as a major.

Strongly agree

__ Mildly agree

_ Neutral

__ Mildly disagree

_

Suggestions for Improvement

If you have any suggestions for improvement of the Accounting Boot Camp, please write them in the space provided below. 